\title{
AVALIAÇÃO QUALITATIVA E PARTICIPATIVA DE PROJETOS: UMA EXPERIÊNCIA A PARTIR DE PESQUISA EM EDUCAÇÃO AMBIENTAL E SANEAMENTO DO MEIO
}

\author{
Helena Ribeiro* \\ Wanda M. Risso Günther** \\ Joyce Maria de Araujo ${ }^{\star \star \star}$
}

\begin{abstract}
RESUMO: A avaliação de projetos de pesquisa em educação ambiental e em saneamento do meio, desenvolvidos em comunidades urbanas e rurais brasileiras, é uma atividade ainda bastante restrita, em que pese sua grande importância acadêmica e prática. Sua relevância é ainda maior quando se trata de pesquisa-ação, em que os pesquisadores desempenham papel ativo na busca de soluções para o equacionamento de problemas encontrados. A possibilidade de tornar disponíveis, às comunidades estudadas, os resultados de investigações, de forma simples e compreensível, pode servir de instrumento para melhor dimensionamento e eficácia de políticas públicas; além disso, fornece respostas aos pesquisadores, que podem embasar suas atuações futuras em realidades semelhantes. O presente artigo baseia-se em avaliação qualitativa e participativa do projeto "Educação ambiental via representações acadêmicas e populares do meio", desenvolvido nos municípios de Espírito Santo do Turvo e Vera Cruz, no oeste do estado de São Paulo, nos anos 1998 a 2001. Concluído o projeto, foram realizadas entrevistas para avaliá-lo com moradores do dois municípios, considerados personagens-chave nas ações locais empreendidas. Empregou-se metodologia qualitativa de pesquisa e roteiro previamente estruturado, com perguntas abertas. Os resultados demonstraram que características locais especificas condicionaram formas peculiares no desenvolvimento do projeto, levando, por conseguinte, a diferenças importantes no tocante à sua ressonância em cada município. Entretanto, de modo diferenciado, o projeto atingiu os objetivos de melhor capacitar os moradores para promover um desenvolvimento sustentável.
\end{abstract}

PALAVRAS-CHAVE: avaliação de projeto, educação ambiental, saneamento do meio, saúde ambiental, desenvolvimento sustentável.

\footnotetext{
* Geógrafa, Mestre em Geografia pela Universidade da Califórnia, Doutora em Geografia Física pela Universidade de São Paulo, Livre-docente em Saúde Pública pela Universidade de São Paulo, Professora Associada do Departamento de Saúde Ambiental, Faculdade de Saúde Pública da Universidade de São Paulo - Rua Silveira Sampaio, 119 - CEP 05656-010 - São Paulo - SP - Brasil Tel. (11) 3066-7712 e (11) 3746-5151 e-mail: lena@usp.br

** Engenheira e socióloga, Doutora em Saúde Pública pela Universidade de São Paulo, Professora Doutora do Departamento de Saúde Ambiental Faculdade de Saúde Pública da Universidade de São Paulo - Av. Dr. Arnaldo, 715 - CEP $01246-904$ São Paulo - SP - Brasil Tel. (11) 3066-7712 e (11) 3082-3842 e-mail: wgunther@usp.br

*** Socióloga, Mestre em Saúde Pública pela Universidade de São Paulo, Doutoranda em Saúde Pública pela Universidade de São Paulo - Av. Dr. Arnaldo, 715 - CEP 01246-904 - São Paulo - SP - Brasil - Tel. (11) 4614-1091 e-mail: joycema@ usp.br
} 
Nas regiões brasileiras inúmeros projetos de pesquisa em educação ambiental e em saneamento do meio vêm sendo desenvolvidos em comunidades, das mais variadas, sem que avaliações sejam realizadas para verificar os resultados de tais projetos, tais como o alcance das atividades, a eficácia dos métodos adotados em seu desenvolvimento, a replicabilidade da metodologia adotada. Em um contexto urbano marcado pela degradação intensa do ambiente construído e dos ecossistemas, uma reflexão acerca de tal degeneração não pode ser realizada sem a análise dos seus determinantes, das formas de organização social que apontam para alternativas de ação segundo a perspectiva da sustentabilidade $e$ dos atores envolvidos nesse processo (JACOBI, 1997 apud JACOBI 2000, p. 14); considerou-se assim que a avaliação participativa desempenha importante papel na identificação e manifestação de atores locais.

A avaliação reveste-se de importância ainda maior quando se trata de pesquisaação, em que "os pesquisadores desempenham um papel ativo no equacionamento dos problemas encontrados, no acompanhamento e na avaliação das ações desencadeadas em função dos problemas" (THIOLLENT, 2000, p. 15). Segundo THIOLLENT, 2000, a pesquisa-ação consiste no relacionamento de dois objetivos: um prático, por meio da contribuição da atuação de atores diversos para melhor equacionamento do problema central da pesquisa; o segundo refere-se ao aumento de conhecimento de determinadas situações, a partir da obtenção de informações que seriam de difícil acesso por meio de outros procedimentos.

Um ponto relevante é que os resultados da pesquisa estejam disponíveis, não só aos pesquisadores e instituições de pesquisa e financiamento envolvidos, como aos participantes da comunidade pesquisada e aos tomadores de decisão sobre políticas públicas e programas, implementados ou a serem desenvolvidos na área estudada. É recomendável, portanto, que os resultados sejam apresentados da forma mais simples e compreensível possível (MAJCHRZAK, 1984), para que sejam compreendidos pelo público leigo, não familiarizado com o linguajar técnico-científico.

Tendo essas idéias como premissas propõe-se a descrever, no presente artigo, a avaliação de um projeto temático de educação ambiental, desenvolvido durante quatro anos em dois municípios localizados no Planalto Ocidental do estado de São Paulo, Espírito Santo do Turvo e Vera Cruz. Pretende-se contribuir para a discussão de metodologias de avaliação de projetos relacionados à temática da saúde ambiental e aos aspectos sócioeconômicos de comunidades urbanas de pequeno porte, com atividades rurais predominantemente rurais. 
O município de Espírito Santo do Turvo localiza-se no km 315 da Rodovia Castelo Branco, no sentido São Paulo-Bauru. Existe como núcleo habitacional e produtivo desde o final do século XIX, chegando a ser importante pólo de desenvolvimento, com cultivo de algodão e amendoim. Hoje detém pequena importância econômica e vive, sobretudo, da lavoura de cana-de-açúcar para produção de álcool e da criação de gado. Em 2000 possuía 3.677 habitantes, $88,9 \%$ dos quais vivendo na área urbana (IBGE, 2000).

O município de Vera Cruz localiza-se na bacia do rio do Peixe, entre os municípios de Marília e Garça, a cerca de $425 \mathrm{~km}$ da capital do estado. Sua economia rural baseia-se na cultura de café, milho, maracujá e seringueira, sendo que $80 \%$ da sua área é ocupada com pastagens. Em 2000 apresentou 11.085 habitantes, com 82,7\% da população vivendo no núcleo urbano (IBGE, 2000).

Uma equipe multidisciplinar de pesquisadores de diferentes instituições (Faculdade de Saúde Pública, Faculdade de Educação, Escola Superior de Agronomia Luiz de Queiroz da Universidade de São Paulo; e Instituto Agronômico de Campinas - IAC) desenvolveu, nas comunidades dos dois municípios, um amplo projeto integrado e multidisciplinar de pesquisa e educação ambiental. $O$ objetivo do projeto foi desenvolver metodologias de pesquisa e de educação ambiental em diferentes campos do conhecimento - educação, saúde pública e saneamento ambiental, ciências agronômicas e questões fundiárias, meio biológico - que contribuíssem para encaminhar soluções ou diminuir os efeitos dos problemas ambientais e sociais enfrentados em cada município, seja por meio de resultados técnicos, seja por intermédio de ações práticas. $O$ projeto contou com a participação das administrações municipais, de organizações representativas da população dos dois municípios e de membros das comunidades locais.

\section{AVALIAÇÃO DO PROJETO TEMÁTICO: ASPECTOS CONCEITUAIS E OPERATIVOS}

A avaliação do projeto temático "Educação Ambiental via Representações Acadêmicas e Populares do Meio Ambiente" baseou-se, em grande medida, em metodologia proposta por I.C.L.E.I. (International Council for Local Environmental Initiatives) e P.N.U.M.A (Programa das Nações Unidas para o Meio Ambiente)' ${ }^{1}$ (I.C.L.E.I., 1998) adaptada por

\footnotetext{
1 A metodologia foi desenvolvida para avaliação do Programa Comunidades Modelo, que orientou e premiou 21 municípios (ou governos locais), em todo o mundo, por seus processos de formulação participativa de Agenda 21 Municipal.
} 
profissionais da Faculdade de Saúde Pública da Universidade de São Paulo à realidade dos municípios envolvidos no projeto temático.

A Educação Ambiental, conforme definida na Lei Federal n. 9.795 (BRASIL, 1999), que instituíu a Política Nacional de Educação Ambiental, caracteriza-se pelos processos por meio dos quais os indivíduos e a coletividade constroem valores sociais, conhecimentos, habilidades, atitudes e competências voltados para a conservação do meio ambiente, bem de uso comum do povo, essencial à sadia qualidade de vida e à sua sustentabilidade.

De acordo com as recomendações da Conferência Intergovernamental de Educação Ambiental, ocorrida em 1977, em Tbilisi, considerada marco significativo na história desse área do conhecimento, os marcos fundamentais da Educação Ambiental são os seguintes: levar os indivíduos e a coletividade a compreender o ambiente natural e o ambiente criado pelo homem (tecnológico, social, econômico, político, histórico-cultural, moral e estético); adquirir conhecimentos, valores, comportamentos e habilidades práticas para participar da prevenção e da solução da gestão ambiental. Para tanto, a Educação Ambiental deve promover uma estreita vinculação entre os processos educativos e a realidade, estruturando suas atividades em torno dos problemas concretos que se impõem à comunidade (DIAS, 1992).

De forma similar à filosofia do projeto, a avaliação também foi embasada na percepção que diferentes atores sociais da comunidade têm acerca da importância de cada participante local no desencadeamento de ações em direção a um "desenvolvimento sustentável". A expressão desenvolvimento sustentável é usada em referência às suas cinco dimensões, propostas por SACHS (1993): ambiental, econômica, social, cultural e espacial.

A avaliação, por sua vez, pode ser compreendida como o delineamento e a obtenção de informações úteis para julgar determinada situação, levantadas com a finalidade de oferecer alternativas de decisão sobre aquela situação. Embora a avaliação deva ser empreendida como uma ação integrada à dinâmica das instituições e ao cotidiano dos atores sociais participantes das intervenções, foram concentradas, no presente estudo, informações acerca dos atores locais envolvidos no desenvolvimento do projeto, nas duas localidades. Quanto ao foco da avaliação, que orientou a construção de categorias de respondentes e a elaboração do instrumento de coleta de dados, foi direcionado às questões estruturais do projeto, especialmente seus objetivos e finalidades; às principais ações 
realizadas em campo, durante o período de implementação; e aos resultados obtidos para a vida da população local (CHIANCA et al, 2001; MARINO, 1998).

Foi realizada então uma pesquisa a partir de entrevista individual, com emprego de roteiro previamente estruturado, formulado com perguntas abertas, elaborado segundo metodologia qualitativa de pesquisa, cujo formulário encontra-se no Anexo 1. As entrevistas foram realizadas com personagens-chave para o desenvolvimento do projeto em cada município, e com alguns membros da população não necessariamente envolvidos com o projeto, mas que vivenciam ou vivenciaram situações representativas da vida social local (PATTON, 1987).

A escolha dos atores para responder às entrevistas deu-se após um trabalho de mapeamento, em cada comunidade, dos participantes que atuaram no projeto, em suas diversas fases, e de não-participantes, de acordo com a inserção institucional e social desses atores nas localidades investigadas, de forma a compor categorias que orientassem o processo de seleção de informantes para a coleta de dados.

Foram identificadas as seguintes categorias de atores locais: agentes do executivo municipal (prefeito, secretários municipais, representantes do legislativo municipal, agentes que atuam em planos e programas locais); agentes de órgãos da administração pública federal ou estadual sediados nas localidades; membros de representação de instituições e entidades colegiadas (conselhos, comitês, fóruns); representações e membros de organizações da sociedade civil; representantes do setor produtivo privado e da economia local; moradores locais (pessoa idosa com mais de 65 anos; mãe ou pai de família com 2 filhos ou mais; mulher casada, viúva ou solteira com menos de 60 anos; jovem estudante; comerciante urbano; trabalhador rural; fazendeiro ou administrador de empreendimento rural), conforme consta no anexo 2.

\section{ESPÍRITO SANTO DO TURVO}

Em Espírito Santo do Turvo, foram realizadas dezenove entrevistas entre os dias 26 a 27 de outubro de 2001, estando então as atividades de campo do projeto terminadas há mais de três meses. Dos entrevistados, cinco (26\%) eram homens e catorze (74 \%) mulheres, de certa forma refletindo o forte envolvimento das mulheres da comunidade com o projeto. Uma das questões de corte para o entrevistado representativo da comunidade 
era que a pessoa "abordada" já tivesse ouvido falar no projeto da USP. No total, dentre os vários moradores abordados, seis trabalhadores rurais do sexo masculino, uma mulher idosa e duas garotas jovens afirmaram não ter ouvido falar no projeto, portanto foram descartados para entrevista pelas pesquisadoras.

Foram entrevistados em Espírito Santo do Turvo: o Prefeito, a Secretária Municipal de Agricultura, o Secretário Municipal de Educação, uma vereadora, a presidente do Clube da 3. ${ }^{a}$ idade, a presidente da Associação das Mulheres de Espírito Santo do Turvo (AMEST), a presidente do Conselho Tutelar da Infância e Adolescência, a diretora da Escola Municipal (1. grau), a coordenadora pedagógica da Escola Estadual (2. grau), uma aposentada, um empresário do comércio municipal, um professor estadual, um fiscal tributário membro da Associação de Moradores do Jardim Canaã, dois adolescentes estudantes dos sexos feminino e masculino (sendo um participante da Associação Amor Exigente), três mulheres (sendo uma participante do Conselho Municipal de Saúde; uma da Associação de Mulheres - AMEST; e uma da Associação de Artesãos - ARTEST); uma dona de casa e uma auxiliar odontológica que havia coordenado os mutirões de limpeza.

Em resposta à questão acerca do que conhece ou ouviu falar sobre o projeto da USP no município, o que se registrou foi:

"Toda comunidade estava ciente do projeto:

..."foram projetos excelentes: o mutirão de limpeza, o estudo do meio, o levantamento de solos do IAC" (Instituto Agronômico de Campinas), segundo resposta da secretária da agricultura).

"Era um projeto de meio ambiente, da limpeza das caixas d'água, da visita na Guacho... Já ouvi falar tanto do projeto!" (mulher participante da Associação dos Artesãos)".

De fato, dos dezenove entrevistados, cinco se lembraram dos mutirões de limpeza das ruas, quintais e caixas d'água; dois ressaltaram a força que o projeto deu para a Associação de Mulheres em seu início; quatro indicaram que era um projeto de meio ambiente; dois mencionaram que o projeto fez o estudo do meio; dois citaram que o projeto objetivava melhorar o ensino; dois que era um projeto de seminários e eventos; um que era de limpeza do córrego; um que era para trazer experiência da Universidade para o município; três responderam que tinham ouvido o pessoal falando, mas não sabiam bem do que se tratava. Por essas respostas, pode-se verificar que, no geral, o sentido do projeto de 
"Educação Ambiental" foi bem compreendido pela comunidade, que identificou seu caracter educativo e de melhoria do meio ambiente, além de sua ligação com ações desencadeadas no município.

A análise dos dados e a interpretação dos resultados permitiram observar que, nas respostas à questão sobre o que aconteceu no município depois que o projeto USP se iniciou, começava a se consolidar, gradativamente, o processo de verificação e comprovação da hipótese inicial da pesquisa: de que uma comunidade mais informada sobre os problemas e potencialidades ambientais de seu município estaria melhor instrumentalizada para superar os desafios em busca de um desenvolvimento sócio-econômico ecologicamente mais equilibrado.

É importante, nesse item, registrar a resposta dada pelo prefeito: "O projeto ajudou muito a participação da população... o projeto deu uma virada no município"; e a resposta dada por uma vereadora de partido de oposição ao prefeito: "O projeto ajudou muito... ele se estendeu para todos os setores. Na Associação de Mulheres muitas eram alienadas $e$ mudaram, mudou a pessoa... eu falo da pessoa humana".

"A comunidade está mais organizada, o projeto despertou lideranças... incentivou as pessoas a estarem iniciando as coisas, principalmente as mulheres, a se sentirem mais capazes de fazer as coisas...", respondeu a presidente do Conselho Tutelar da Infância e Adolescência.

Essas respostas ressaltam, sobretudo, o envolvimento da população nas questões municipais e seu desenvolvimento pessoal.

Outro ponto muito enfatizado foi a melhora do nivel de ensino, a partir da reciclagem dos professores e da experiência de estudo do meio na fazenda Guacho, que no ano de 2001 estava se repetindo como iniciativa independente do projeto, na área urbana do município:

“os alunos aprenderam muito como reflexo do que os professores aprenderam"...

Outros se lembraram da maior conscientização das pessoas para com os problemas ambientais e a higiene e limpeza.

O sentimento geral era que tudo melhorou no município. Dos dezenove entrevistados, dezessete tiveram respostas bastante positivas. Somente duas entrevistadas do sexo 
feminino, uma jovem de quinze anos e uma dona-de-casa esposa de trabalhador rural diarista, não conseguiram apontar acontecimentos positivos ocorridos após o início do projeto. A jovem, que morava numa casa bem simples no centro, disse que continuava a haver pessoas com fome e com frio; e a dona-de-casa lembrou que a saúde não melhorou.

O acesso a informações técnico-científicas sobre o município foi um dado importante ressaltado pela secretária de agricultura, pois instrumentalizou diferentes órgãos do poder público a desenvolver projetos e programas mais consistentes. A fala da entrevistada ilustra esse fato: ..."o levantamento de solos, da vegetação com porcentagens, etc., da flora e da fauna foi excelente para o município. Ele é muito usado... Hoje se tem dados concretos e reais do município, com os problemas identificados, como as voçorocas... Daí dá para agir, fazer projetos e cobrar dos agricultores... mas os próprios agricultores, com o programa de micro-bacias, que foi possivel graças aos mapas de solos, estão cientes da necessidade de reflorestar mata ciliar"...

Por outro lado, duas respostas equivocadas foram dadas quanto ao que aconteceu em Espírito Santo do Turvo. Um jovem disse que o projeto "tá acabando com a dengue". De fato, o município nunca teve caso de dengue, mas como aí foram detectados focos do mosquito transmissor e a região teve inúmeros casos, foi feito, como prevenção à doença, um amplo mutirão de limpeza nos quintais, ruas e praças do município, com participação de funcionários da prefeitura, professores e alunos da USP, alunos das escolas do município e voluntários da comunidade. A segunda resposta imprecisa veio de uma mulher que trabalha em costura na Associação de Mulheres, a qual indicou que o projeto fez cursos para a associação, sendo que antes tinha mulher que nem sabia o que era máquina industrial. $\mathrm{Na}$ realidade, os cursos de costura industrial não foram organizados pelo projeto, e sim pela Associação, em parceria com o SEBRAE (Serviço Brasileiro de Apoio às Micro e Pequenas Empresas) e o governo, sendo que as máquinas de costura industrial foram obtidas pelo prefeito junto à Receita Federal.

Respondendo à questão subseqüente, dentre as situações que mudaram no município depois que o projeto começou, foram lembrados:

- melhoria na educação na escola;

- melhoria na limpeza;

- o fato de não jogarem mais sujeira no rio;

- melhoria no divertimento e lazer;

- volta de obras e construções;

- asfaltamento de ruas. 
Quando solicitados a dizer a causa dessas mudanças, foi respondido que o Município mudou porque:

- a comunidade cobra as coisas;

- o pessoal está com mais facilidade de se agrupar;

- mudou a cara do município, mas as pessoas também mudaram;

- aumentou a conscientização;

- o município mudou para melhor;

- houve mudança no visual;

- hoje é melhor para trabalhar;

De todos entrevistados só um jovem achou que não houve mudança no município. Todos os outros consideraram ter havido mudanças positivas.

Dentre os aspectos que não mudaram, foram lembradas: a falta de remédios no Posto de Saúde; a saúde que ainda é precária; e a lama que corre para o centro da cidade quando chove.

Além desses três pontos, foi ressaltado por uma pessoa que só não mudaram as coisas que o povo não levou a sério e não quis; e por outro lado, o aspecto social no setor da administração da cidade é que não se desenvolveu como deveria. As restantes pessoas consideram que tudo mudou na cidade, ou não conseguiram se lembrar de algo que não havia sido mudado nesse período, com exceção do jovem que disse que bastante coisa não mudou, mas não indicou o que não mudara.

No que tange à questão sobre alguma mudança ocorrida no trabalho da Prefeitura Municipal, depois do início do projeto, dezoito pessoas indicaram que o trabalho mudou para melhor e só uma afirmou não saber, pois não participa da prefeitura por ser de outro partido, diferente do partido do prefeito. Já para o prefeito, "a maior contribuição foi encontrar parceiros para discutir as políticas e aumentar a participação da sociedade civil, pois o projeto tinha muita credibilidade".

Os moradores indicaram as seguintes mudanças positivas: o paisagismo na beira do rio, a regularização da coleta de lixo, o asfaltamento de ruas, melhorias na educação de um modo geral, o melhor atendimento público por parte dos funcionários da prefeitura, mais gente trabalhando, máquinas novas em operação nas localidades, a dinamização dos serviços, a maior cobrança de Polícia Militar para fiscalização. Outros lembraram que a 
grande mudança foi no modo de agir, no modo das pessoas trabalharem e agirem; e duas pessoas ressaltaram as reuniões mensais do prefeito com os representantes dos movimentos e associações, para prestar contas, ouvir necessidades e encaminhar decisões.

Referindo-se à percepção sobre o aumento da preocupação das pessoas do município com relação ao meio ambiente, só uma jovem respondeu negativamente; uma pessoa respondeu não saber, pois não havia conversado sobre isso; e uma terceira disse que foi feito um estudo sobre o meio ambiente, mas que por enquanto, não teve resultado. As restantes dezesseis pessoas foram unânimes em considerar que aumentou muito a preocupação frente ao meio ambiente em Espírito Santo do Turvo. Foi lembrado, sobretudo, o estudo do meio com as escolas, que agora continua com os professores locais, apesar do término do projeto. Também foram indicados: a maior preocupação de todos com a limpeza; o plantio de árvores e plantas; o trabalho da rádio local, que vem continuando a lembrar as pessoas acerca dos aspectos ambientais. Foi indicado também que, antes do projeto, não se sabia nem o que era meio ambiente, e agora havia mudado a consciência do povo.

Com respeito à participação em atividades desenvolvidas pelo projeto, dentre os - entrevistados, sete pessoas relataram nunca ter participado de alguma reunião do projeto no município, mas doze relataram ter participado de reuniões. Dentre os assuntos tratados nessas reuniões, lembrados pelos respondentes, estão: mutirão de limpeza das caixas d' água; alcoolismo; meio ambiente e higiene em geral; educação; coleta de lixo; água; saúde; agricultura e lazer. São expressivas duas respostas dadas: "os assuntos foram colocados de forma abrangente e todas as reuniões serviam para alguma coisa, sempre se aprendia algo"... e ..."foi falado sobre tudo... a gente aprendeu tanta coisa com o projeto que ajudou muito o município"... Dentre as entrevistadas, duas relataram participar das reuniões mensais do projeto.

Os sete entrevistados que não participaram de reuniões também não participaram de nenhuma atividade do projeto, com exceção de três deles, que relataram ter ajudado no mutirão de limpeza de caixas d' água e quintais, quando esse passou em suas casas. Além desses sete, mais oito entrevistados relataram não ter participado ativamente de nenhum mutirão de limpeza ou atividade de campo do projeto. Dentre os cinco que participaram de atividades de campo, dois participaram do mutirão catando lixo, um participou de atividade de levantamento de solo no campo e dois participaram do estudo do meio na Fazenda Guacho. 
Essa baixa proporcionalidade dos entrevistados em atividades práticas do projeto é interessante, quando cotejada à ressonância favorável que essas atividades tiveram no município, conforme verificado nas respostas às questões anteriores.

Os respondentes que participaram do primeiro mutirão, organizado pelo projeto, participaram também do segundo mutirão, de iniciativa da Prefeitura e organizaram o terceiro, que ocorreu no final de 2001. Por outro lado, mais seis entrevistados responderam estar cientes da continuidade anual dos mutirões, apesar de não terem tido participação nesses eventos; e três responderam não saber dizer se houve mais mutirões, além daquele mutirão inicial do projeto.

Dentre os dezenove entrevistados, dezesseis afirmaram ter havido alguma mudança pessoal para eles, após o início do projeto da USP no município; dois afirmaram não ter havido; e um disse não se lembrar.

Das mudanças pessoais relatadas aparecem, de forma predominante, a maior conscientização e a maior participação do respondente na comunidade e com os assuntos do município. Consideraram efeitos secundários: aprendizado de participação comunitária e de realizar reuniões; sentimento de utilidade; melhores relacionamento pessoal e comunicação; e até comportamento mais conservacionista. Um outro grupo de pessoas percebeu que as melhorias no meio ambiente do município trouxeram efeitos em outros aspectos da vida municipal: saúde das crianças, atividade comercial, finanças. Uma entrevistada relatou: "Fiquei mais inteligente".

Na opinião de dezoito, dentre os dezenove entrevistados, as pessoas estão cuidando mais do meio ambiente no município (só uma respondeu "mais ou menos"). O prefeito considerou que, sobretudo na área rural, os agricultores e trabalhadores estão tendo atitudes mais conservacionistas, em virtude dos cursos ministrados sobre reciclagem de embalagens de agrotóxicos, conservação de solo e preservação da mata ciliar; na área urbana, achou que os cuidados poderiam progredir.

Dezoito entrevistados também concluíram que o jardim das casas está sendo mais bem cuidado pelos moradores; e um informante disse não ter dados para responder, mas que talvez os jardins estejam mais bem cuidados. $O$ prefeito ponderou que as atividades educativas tiveram maior efeito quando foram acompanhadas de outras ações da prefeitura, tais como o asfaltamento de ruas. Afirmou que no Jardim Zanata, onde ainda não há asfalto, 
o cuidado com o quintal das casas continua sendo precário. Já nas ruas que foram asfaltadas, o maior cuidado é percebido facilmente. Essa fala do prefeito é particularmente importante, pois reforça a idéia de que a educação, empreendida de modo isolado e uni-institucional, apresenta resultados bem menos significativos do que quando associada a ações do poder público. A integração interinstitucional entre educação ambiental e ações das políticas públicas promove maior motivação e favorece mudanças de atitudes, de forma mais evidentes.

A água usada pelas pessoas que pescam ou tomam banho foi considerada então em melhores condições por quinze entrevistados. Dois entrevistados alegaram não saber se melhorou; e outros dois consideram-na em igual condição à do início do projeto. É preciso lembrar que, no início do projeto foi aplicado um questionário em amostra aleatória da população de Espírito Santo do Turvo, para verificar o que entendiam por meio ambiente e o que percebiam como problema ambiental no município ${ }^{2}$. Vinte e três por cento dos respondentes haviam indicado o rio poluído, que correspondeu ao problema mais percebido pelos moradores. A poluição hídrica era associada à diminuição da pesca e às doenças de pele adquiridas pelas crianças, uma vez que o córrego Rangel (que corta o centro urbano) e o rio Turvo constituem as principais áreas de lazer do município, para o banho de rio e pescaria.

Durante o decorrer do projeto, várias ações foram desenvolvidas pela SABESP (Companhia de Saneamento Básico do Estado de São Paulo) e pela Prefeitura Municipal nos corpos hídricos. A SABESP controlou o lançamento de esgotos clandestinos no córrego do Rangel e, em 2001, finalmente inaugurou um sistema de tratamento de esgotos, de modo que esses não são mais jogados in natura no rio Turvo, como era feito até então. A prefeitura, por sua vez, realizou obras de dragagem no trecho urbano do córrego do Rangel, canalizou as águas pluviais que nele deságuam, limpou suas margens e realizou plantio de árvores, com ajuda de crianças da rede escolar, em toda sua extensão, além de ter construído calçada para passeio e caminhadas da população.

Concomitantemente a essas ações, a equipe do sub-projeto de saneamento ambiental realizou análises bacteriológicas e físico-químicas em oito pontos da rede hidrográfica municipal, com intervalos aproximados de três meses. Os resultados dessas análises indicaram diminuição significativa da contaminação por coliformes fecais e, portanto,

20 questionário bseou-se naquele desenvolvido por PELICIONI (1998), com adaptações. 
melhoria nas condições de balneabilidade, com eliminação de riscos à saúde pública. Foram também registradas melhorias nas condições ecológicas dos corpos d'água, com diminuição da demanda bioquímica de oxigênio (DBO) e aumento do oxigênio dissolvido (OD).

No final de 2001 foi construída pela prefeitura uma área de lazer, constituída por uma prainha artificial, recoberta de areia importada, como alternativa de recreação para os moradores, na área urbana do Córrego do Rangel.

A maioria dos entrevistados demonstrou saber que agora existe tratamento de esgotos no município. Além disso, muitos lembraram que a maior conscientização faz com que as pessoas não joguem mais resíduos no rio e no córrego.

"Antes o córrego era muito sujo, jogavam muito lixo. Agora está tudo limpinho" (entrevistada de 55 anos).

“Está melhor, antes era só sujeira, não era tratado nem cuidado. Tudo quanto é porcaria era jogada lá" (entrevistada de 56 anos, presidente do Clube da 3. Idade).

Duas preocupações, no entanto, foram levantadas. Quatro entrevistadas mostraram receio de afogamento das crianças na prainha. Duas pessoas se referiram à diminuição da pesca no Rio Turvo, com o fim do lançamento do esgoto sem tratamento, o qual representava oferta de matéria orgânica peixes no local de lançamento; conseqüentemente, havia maior concentração de peixes nesse ponto do rio. De fato, por ocasião das coletas de água no córrego, no local de lançamento de esgoto pela SABESP, era freqüente encontrar pessoas com mais de uma vara de pescar bem naquele ponto. Isso se explica pela maior quantidade de nutrientes, presentes naquele local, que desencadeava crescimento de fitoplâncton e atraía peixes. No entanto, pelo ângulo da saúde pública, o saneamento traz vantagens bastante demonstradas na literatura especializada (HELLER, 1997).

Cem por cento dos entrevistados consideraram que, depois que o projeto da USP começou, a coleta de lixo e a limpeza da cidade melhoraram. Associam assim que o processo de conscientização, ocorrido no decorrer das ações do projeto referidas à questão dos resíduos sólidos, favoreceu o desencadeamento de um programa municipal mais adequado de gerenciamento do lixo, com coleta regular três vezes por semana feita por caminhão compactador e construção de aterro em vala, em substituição à destinação dos resíduos urbanos a céu aberto, em sulco de erosão; e propiciou ainda o desenvolvimento de comportamentos mais adequados da população em relação à limpeza urbana. 
Quando confrontados com a pergunta: "O que faltou ao projeto da USP?", cerca de $1 / 3$ dos entrevistados (seis respondentes) considerou que o projeto cumpriu seus objetivos e não faltou nada. Três consideraram que poderia ter tido mais reuniões educativas; três acharam que vai fazer falta um acompanhamento posterior das ações peła equipe do projeto; duas pessoas atribuíram ao projeto ações não ligadas a ele, como ter mais remédio no Posto de Saúde e asfaltar todas as ruas. Provavelmente essas respostas se referem ao questionário aplicado no início do projeto, conforme já mencionado; nesse levantamento, as pessoas indicavam o que consideravam problema ambiental no município. Naquela ocasião, o lixo foi indicado por $17 \%$ dos pesquisados e a falta de asfalto e sujeira nas ruas igualmente, por $17 \%$ dos respondentes. Presumivelmente teria permanecido, em algumas pessoas, a expectativa de que o projeto resolveria todos os problemas.

No final, alguns entrevistados mencionaram aspectos ainda não abordados pelas pesquisadoras, que consideraram importante no projeto da USP.

Segundo o prefeito:

“Esse projeto teve pessoal muito comprometido que não vinha só para aprender"... "o projeto superou o que se esperava"...

Segundo outras pessoas:

"O que foi mais importante foi as pessoas do projeto que vieram... não se importavam com nossa raça, religião... falavam e sentiam como nós".

"O projeto integrou a comunidade toda... ele deu uma visão muito boa sobre a importância do meio ambiente, sobre qualidade de vida".

"Foi muito gratificante participar dos seminários e ver tudo o que foi feito".

"O projeto foi bem feito, bem trabalhado, os cursos dados, só não tirou proveito quem não quis".

\section{VERA CRUZ}

Em Vera Cruz foram realizadas doze entrevistas entre os dias 21 e 23 de novembro de 2001. Foram entrevistados, como representantes do poder público municipal e de órgãos e agências da administração pública em geral, sediados na localidade: o prefeito, a secretária 
de saúde, o secretário de agricultura e meio ambiente e a coordenadora de cultura; um diretor de escola municipal, o diretor da Escola Técnica Agrícola, uma professora de $2 .^{\circ}$ grau e um professor da Escola Técnica Agrícola. Também foram entrevistados dois alunos da Escola Técnica Agrícola, um morador do bairro de Vila da Paz e um membro do Conselho Municipal da Infância e Adolescência. Devido às características demográficas, sócioeconômicas e culturais de cada localidade, o desenvolvimento do projeto ocorreu de forma diferenciada nos dois municípios. Assim uma maior participação em atividades no meio rural e na Escola Agrícola levou a que, nesse município, maior número de entrevistados fossem ligados a atividades agropecuárias.

A aplicação da pergunta de corte permitiu observar, em Vera Cruz, a ocorrência de maior grau de dificuldade para selecionar, como respondentes, pessoas familiarizadas com o projeto. A interpretação dessa ocorrência apontou na direção de alguns fatores, tais como: as atividades aí desenvolvidas na área urbana foram mais esporádicas; as ações de saneamento se concentraram no bairro Vila da Paz; não houve um entrosamento entre participantes do projeto e o prefeito, cuja atuação esteve limitada a duas entrevistas no decorrer de toda a pesquisa, sendo que não participou de reunião com os integrantes do projeto e a comunidade; houve predominância de atividades no meio rural; o município conta com maior população (três vezes a de Espírito Santo do Turvo); as ações municipais foram em número reduzido, em Vila da Paz, no decorrer da implementação do projeto.

Em Vila da Paz, onde $25 \%$ das residências haviam recebido os pesquisadores para entrevistas e levantamento das condições de saneamento domiciliar, por ocasião da deflagração do projeto, oito pessoas contatadas no domicílio declararam não ter ouvido falar, ou não se lembrar do projeto. Presumivelmente tal fato seja decorrente da alta rotatividade de seus moradores, na maior parte diaristas de atividades rurais; ou porque, como mencionado, houve poucas ações do poder público no bairro, após o levantamento das percepções sobre os problemas ambientais, feito pelos pesquisadores na etapa inicial do projeto, e mesmo durante as primeiras reuniões com moradores da área.

Ao contrário do que aconteceu em Espírito Santo do Turvo - onde o prefeito baseou seu programa de governo fortemente em ações de atendimento às expectativas da população avaliadas na pesquisa inicial, e foi reeleito - em Vera Cruz há um novo prefeito, de outro partido político, a partir de 2001. O novo prefeito alegou não ter conhecimento do projeto da USP em Vera Cruz, nem ter recebido, da administração anterior, os resultados e produtos do projeto, na forma de relatórios e mapas, entregues ao executivo municipal então em 
exercício. "O pessoal foi embora e levou tudo... só deixaram gavetas vazias" (prefeito atual).

Já os novos secretários municipais responderam ter ouvido falar do projeto em aspectos específicos.

"Teve levantamento de solos que está na Casa da Lavoura” (secretário de agricultura e meio ambiente).

"Teve trabalho com as escolas, com a Escola Agrícola e com a saúde... não sei detalhes, mas na Secretaria de Saúde tem cópia de um relatório" (secretária de saúde).

"Trabalhava com crianças carentes, com agricultores e proprietários agrícolas" (coordenadora da cultura).

Por outro lado, os entrevistados vinculados ao sistema educacional demonstraram bom conhecimento do projeto e das ações desenvolvidas junto aos professores e alunos.

Dos doze entrevistados, sete não consideraram haver resultados do projeto, enquanto cinco indicaram, como resultado, maior conscientização das pessoas para questões ambientais, em especial dos agricultores; melhorias no aterro de lixo; o conhecimento do que está acontecendo no município em termos de meio ambiente; o ensino sobre questões ambientais nas escolas; coleta seletiva de lixo na escola; formação de uma associação de produtores rurais da micro-bacia do Ribeirão Água F; convênios da Prefeitura com o Estado e a União para melhorias na área de saneamento básico (água, esgoto e resíduos sólidos).

Em resposta à questão sobre o que não mudou, seis não responderam; um disse que nada mudou; e os cinco restantes indicaram aspectos que não haviam sido modificados: a coleta de lixo, que continua com caminhões basculantes e derramando lixo nas estradas, e o destino do lixo. Fora o tema lixo, só uma pessoa levantou o fato de que a educação é um processo que tem que ser alimentado. Referindo-se à instituição escolar, esse entrevistado acrescentou que os alunos que receberam educação ambiental, saíram da escola; entretanto o programa deveria continuar com os professores que ficaram.

Com relação às mudanças no trabalho da prefeitura, foram relatadas: melhorias no sistema de coleta de esgotos, apesar das deficiências ainda existentes; mutirões de limpeza na cidade, como forma de combate à dengue; melhorias no aterro de lixo; construção de um centro de triagem de lixo para reciclagem, que não foi colocado em operação; melhorias na qualidade da água de abastecimento; plantio de árvores nas escolas. 
Nove, dentre os doze entrevistados, consideraram que a população está mais preocupada hoje com relação ao meio ambiente. Essa maior preocupação evidencia-se no trabalho nas escolas, na maior preservação das matas, na melhor limpeza da cidade pela prefeitura, em maior plantio de árvores (sobretudo nas margens do rio das Garças), nas reclamações e exigências que a população faz.

Seis pessoas, dentre os entrevistados, haviam participado de reuniões do projeto no município e se lembravam dos temas tratados: relatório sobre a fauna e a flora, apresentação de resultados do projeto, preparação de mutirão de limpeza de córrego, árvores e meio ambiente e qualidade das águas.

Cinco entrevistados haviam participado de variadas atividades de campo do projeto: visita ao lixão e ao rio das Garças, implantação de horta na escola, mutirão de limpeza do córrego, organização do mutirão de limpeza, levantamento dos solos e pesquisa sobre a flora. Essas atividades envolveram alunos das escolas municipais ou da Escola Agrícola; além disso, o mutirão de limpeza do córrego envolveu produtores rurais.

Quatro entrevistados que participaram dos mutirões de limpeza com a equipe do projeto afirmaram que, em 2001, foi organizado novo "arrastão"3 nas áreas urbana e rural e no rio das Garças, com apoio da prefeitura e da SUCEN (Superintendência de Controle de Endemias).

Dos doze entrevistados, oito afirmaram que observaram mudanças neles próprios, após o início do projeto. As mudanças enfatizadas foram: maior conhecimento e preocupação com as questões ambientais; maior participação em atividades voltadas à melhoria do ambiente, tais como realização de palestras sobre o tema e organização de atividades nas escolas; envolvimento da família do informante, com adoção de atitudes e procedimentos mais adequados e higiênicos nas suas casas e propriedades; melhoria nas decisões sobre assuntos relativos ao meio ambiente.

A maior parte dos respondentes considera que as pessoas, em todos os segmentos, estão cuidando mais do meio ambiente em Vera Cruz. A secretária de saúde ilustrou esse maior cuidado com os resultados obtidos no controle da dengue. Após ter tido um surto epidêmico da doença, em meados da década de 1990, nenhum caso foi registrado em 2000 e em 2001. Alguns afirmaram que, apesar do maior cuidado, ainda há muito a caminhar nesse sentido.

3 Arrastão é o nome usado nos municípios para os mutirões de limpeza. 
No entanto, o morador de Vila da Paz acha que está tudo a mesma coisa. Essa resposta é importante, pois corrobora a opinião do prefeito do outro município pesquisado Espírito Santo do Turvo - que afirmou que só notou hábitos mais cuidadosos nos moradores de bairros onde a prefeitura também fez melhorias e que, portanto, só a educação ou só as melhorias, isoladamente, eram insuficientes. Era preciso haver uma conjugação dos dois fatores, para os resultados serem perceptíveis. Em Vila da Paz, como já dito, houve poucas melhorias de infra-estrutura e dos serviços públicos aparentes, durante os anos em que o projeto foi desenvolvido, portanto, as ações educativas do projeto também não tiveram ressonância. Algumas melhorias se restringem a moradias isoladas, cujos proprietários construíram muros e calçadas. A prefeitura instalou rede de coleta de esgotos em Vila da Paz, mas não foi construída a estação elevatória, conseqüentemente, o funcionamento do sistema é muito precário, com constantes entupimentos e vazamento de esgotos nas ruas.

Os entrevistados consideraram, na sua quase totalidade, que os quintais e jardins das casas da cidade estão mais conservados. Um deles lembrou que o arrastão ajudou nesse sentido; outro enfatizou que o atual prefeito está cuidando muito bem das praças e ruas, e que isso acaba se refletindo no jardim das casas, pois motiva as pessoas a ter moradias mais cuidadas.

Com relação a ter havido melhorias nas condições da água usada pelas pessoas, duas não responderam; quatro consideraram que a água está a mesma coisa; os seis restantes indicaram saber que a água estava fora dos padrões de potabilidade até o início de 2001, mas que na época (novembro de 2001) estava adequada ao consumo. O prefeito informou que foram comprados novos dosadores de cloro e de flúor para a água de abastecimento, que é submetida à análise do Instituto Adolfo Lutz a cada dois meses e encontra-se dentro dos padrões de potabilidade.

Foram unânimes as opiniões dos doze entrevistados, de que melhoraram tanto a coleta de lixo como a limpeza da cidade. Alguns ressaltaram que a limpeza pública é uma prioridade do atual prefeito e que, por isso, o aspecto visual da cidade ficou melhor. Um professor da Escola Técnica Agrícola ressaltou que "o município nunca foi assim tão sujo, mas passou-se a coletar em pontos que não eram coletados e o lixo era despejado em local não-adequado, dentro de uma boca de lobo, por exemplo. Depois passou a ser armazenado em sacos e coletado pelo caminhão. Mudou o método. As mudanças se deram devido a cobranças da população". Outro entrevistado disse que foi o medo da dengue que melhorou a limpeza dos quintais. 
Em resposta à pergunta sobre o que faltou ao projeto, seis responderam não saber. Os outros indicaram que "faltou tempo", "faltou continuidade", "faltou mais motivação para que tivesse mais gente da cidade envolvida", "faltou treinamento", "faltou maior divulgação do projeto e de seus resultados para envolver mais famílias", "foi mais um diagnóstico, poderia ter tido mais ações para sanar problemas". E o morador da Vila da Paz respondeu: "aqui falta tudo".

A primeira interpretação dos resultados das avaliações dos entrevistados indica que, de um modo geral, os objetivos educativos em relação aos cuidados com o meio ambiente foram, em parte, atingidos. No entanto, uma análise mais acurada desses resultados aponta na direção de alguns condicionantes, que teriam atuado como fatores indutores na configuração da avaliação dos respondentes. Pode-se considerar que um nível mais alto de conhecimento dos problemas ambientais municipais, por parte da população, poderia favorecer a adoção de atitudes mais positivas frente às questões ambientais e propiciar, por suposto, maior cobrança de ações do poder público para a solução de problemas. Por outro lado, o maior conhecimento de problemas ambientais locais poderia ocasionar reações de frustração aos moradores locais, quando não há ações decorrentes de enfrentamento das dificuldades identificadas.

Todavia, a partir das respostas de alguns dos entrevistados, que tiveram conhecimento mais efetivo dos procedimentos e dos resultados do projeto, é possível deduzir que a pesquisa deixou sementes importantes no município de Vera Cruz. Estão transcritas abaixo algumas falas que permitem exemplificar a consideração acima:

"O ponto mais alto do projeto foi o envolvimento das escolas e dos alunos que gerou a mobilização de toda comunidade".

"Os dados de flora e fauna passados vieram a reforçar o conhecimento para desenvolvimento das atividades escolares".

"O projeto foi muito importante para toda a população, para o próprio município. Também acho que conseguimos envolver mais as escolas, e que poderíamos ter um método de envolver mais a população".

"Quando a gente fazia alguma coisa que não era correta, os professores compreenderam e orientaram". o esgoto".

"O prefeito não fez nada aqui (Vila da Paz)... mas diz que no próximo ano vai fazer

"A participação no mutirão foi muito boa". 
"Os levantamentos do IAC (Instituto Agronômico de Campinas) estão na Casa da Lavoura servindo para projeto de micro-bacia no Água F".

"Foi muito bom para o município o projeto, em todos os aspectos. E para a escola particularmente. Trouxeram um tema esquecido para discussão, o rio das Garças, que foi morto e querem recuperá-lo".

De fato, em entrevista realizada em novembro de 2001, o novo prefeito informou que há inúmeras obras e ações em andamento em Vera Cruz para melhorias das condições de saneamento. Foi construído aterro em vala para os resíduos sólidos urbanos ${ }^{4}$; está em construção um sistema de tratamento de esgotos com recursos do FEHIDRO (Fundo Estadual de Recursos Hídricos); já foram construídas duas elevatórias para transporte de esgotos sanitários, uma delas em Vila da Paz, só faltando a parte elétrica para entrar em operação (resolvendo um dos problemas mais sérios do bairro, que era o esgoto a céu aberto, conforme sua população indicou na pesquisa realizada no início do projeto temático). Informou também o prefeito que, assim que entrarem em operação as lagoas de tratamento de esgotos, terá início a recuperação da mata ciliar do rio das Garças, para conter os processos erosivos.

\section{CONSIDERAÇÕES FINAIS}

Em que pesem as diferenças quanto ao desenvolvimento do projeto e aos resultados obtidos, em cada localidade, a partir da avaliação qualitativa e participativa complementada por dados técnicos disponíveis, pode-se considerar que o projeto temático atingiu seus objetivos principais de, através das representações das populações locais e dos diagnósticos técnico-científicos, promover um amplo processo de educação das comunidades envolvidas, seja no âmbito escolar institucional, seja fora da escola. Moradores de ambos os municípios reconhecem-se mais capacitados para promover um desenvolvimento sócio-econômico mais sustentável, em várias de suas dimensões: ecológica, econômica, social, cultural e também espacial, por meio da eliminação dos bolsões críticos de insalubridade.

A avaliação do projeto propiciou a obtenção de respostas, aos pesquisadores, aos formuladores de políticas públicas e aos educadores, sobre a validade das ações empreendidas, as limitações enfrentadas e, sobretudo, possibilitou o estabelecimento de patamares mais concretos para continuidade de ações nos dois municípios. Além disso, a

4 Conforme verificado no local, suas condições de operação ainda não se encontram completamente adequadas. 
avaliação qualitativa participativa possibilitou a sistematização de resultados em um conjunto de informações, passível de ser utilizado na replicabilidade da experiência, em inúmeras localidades brasileiras que enfrentam problemáticas semelhantes de degradação ambiental, carência de infra-estrutura de saneamento e insuficiência de oportunidades econômicas.

\section{REFERÊNCIA BIBLIOGRAFIA}

BRASIL. Lei n.o 9.795, de 27 de abril de 1999. Dispõe sobre a educação ambiental. Institui a Política Nacional de Educação Ambiental e dá outras providências. Diário Oficial da União, Brasília, DF, 28 abr 1999.

CHIANCA, T; MARINO, E; SCHIESARI, L. Desenvolvendo a cultura da avaliação em organizações da Sociedade Civi. São Paulo, Global. 2001 (Coleção Gestão e Sustentabilidade).

DIAS, G. F. Educação ambiental: princípios e práticas. São Paulo, Editora Gaia, 4. a ed., 1992.

HELLER, L. Saneamento e saúde. Organização Pan-Americana de Saúde, Brasília, 1997.

INSTITUTO BRASILEIRO DE GEOGRAFIA E ESTATÍSTICA - IBGE. Censo Demográfico, 2000. Disponível em: http://www.ibge.gov.br/ibge/estatistica/populacao/censo2000/ sinopse acesso em 13/09/2001.

INTERNATIONAL COUNCIL FOR LOCAL ENVIRONMENTAL INITIATIVES - ICLEI. ModeI Communities Programme Case Studies. Toronto, 1998.

JACOBI, P. Cidade e meio ambiente: percepções e práticas em São Paulo. São Paulo: Annablume, 2000.

MAJCHRZAK, A. Methods for Policy Research. California, Sage Publications, 1984. (Applied social research methods series; vol. 3).

MARINO, E. Manual de avaliação de projetos sociais. Belo Horizonte, Instituto Ayrton Senna. 1998.

PATTON, M. Q. Qualitative evaluation methods. Beverly Hills, Sage Publications, 1987.

PELICIONI, A F. Educação ambiental na escola. São Paulo, 1998. [Dissertação de Mestrado em Saúde Pública, Faculdade de Saúde Pública da Universidade de São Paulo] 
SACHS, I. Estratégias de Transição para o século XXI. In BURSZTYN, M. (org.) Para pensar o desenvolvimento sustentável. São Paulo, Brasiliense, 1993.

THIOLLENT, M. Metodologia da pesquisa-ação. São Paulo, Cortez, 2000.

\title{
QUALITATIVE AND PARTICIPATORY PROJECT EVALUATION: AN EXPERIENCE BASED ON ENVIRONMENTAL EDUCATION AND ENVIRONMENTAL SANITA- TION RESEARCH
}

\begin{abstract}
SUMMARY: Project evaluation on environmental education and sanitation developed in Brazil has been very little used despite its academic and practical importance. Its relevance is even greater for research-action projects where investigators play an active role in search for solutions of the existing problems. Publicizing the research results to studied communities may help them to better plan future actions. This article is based on a qualitative and participatory evaluation of the project "Environmental education through social representations and technical information" developed in two municipalities in the western region of the state of Sao Paulo - Espírito Santo do Turvo and Vera Cruz - during the 1998-2001period. Results indicated that the local aspects contributed for different forms of project development and different evaluations by the studied communities. Nevertheless, in different ways, the project achieved its main objective, which was to prepare the local inhabitants for the promotion of a more sustainable development.
\end{abstract}

KEYWORDS: project evaluation, environmental education, environmental sanitation, environmental health, sustainable development 


\section{ANEXOS}

Roteiro da entrevista individual de campo utilizado nos dois municípios.

ROTEIRO DE ENTREVISTA INDIVIDUAL

Município: ESPÍRITO SANTO DO TURVO（） VERA CRUZ（）

\section{DADOS GERAIS DO (A) ENTREVISTADO (A)}

Nome completo do (a) entrevistado (a) . . . . . . . . . . . . . . . . . . ................ Sexo: Masc. ( ) Fem. ( )

Escolaridade: . . . . . . . . . . . . . Idade: . . . anos

Endereço (Rua, bairro, CEP, telefone se tiver) . . . . . . . . . . . . . . . . .

Qual é a atividade de trabalho do Sr. (da Srä., sua) aqui no município? (Detalhar: tem vínculo empregatício? É aposentado? O trabalho é permanente/ temporário? E outros) . . . . . .

O Sr. (a Srä., você) participa de alguma associação, entidade ou movimento aqui no município? R) Não ( ) $\operatorname{Sim}($ ) Qual? . . . . . . . . .

1. O Sr. (a Sra‥, você) conhece ou já ouviu falar do Projeto da USP aqui no município?

R) Não ( ) (Encerre a entrevista)

Sim, conhece ou já ouviu falar ( ) O que o Sr. (a Srä., você) conhece ou ouviu falar sobre o Projeto da USP aqui no município? . . . . . . . . . . . . . . . . . . . . . . 
2. Na sua opinião, o que aconteceu no município depois que o Projeto da USP começou? R) . . . . . . . . . . . . . . . . . . . .

(Continuação: explore) O Sr. (a Srª., você) acha que mudou alguma coisa no município depois que o Projeto USP começou? Como era antes? . . . . . . . . . . . . . . . . .

(Continue a explorar) E o que o Sr. (a Srª., você) acha que não mudou no município depois que o Projeto da USP começou?

3. Na opinião do Sr. (da Srª ), aconteceu alguma mudança no trabalho da Prefeitura Municipal depois que o Projeto da USP começou no município?

Não ( )

Sim ( ) E que mudança aconteceu no trabalho da Prefeitura depois que o Projeto da USP começou aqui?

4. Depois que o Projeto da USP começou aqui, o Sr. (a Sràn., você) percebeu alguma preocupação das pessoas com relação ao meio ambiente?

Não percebeu/ não sabe dizer/ não se lembra ( )

Sim ( ) E como foi que o Sr. (a Srä., você) percebeu essa preocupação das pessoas? . . . . . . . . . . . . . . . O Sr. (a Sra reunião do Projeto da USP neste município?

R) Não participou de nenhuma reunião do Projeto da USP ( ) (Pule para pergunta 6) Sim, participou de reunião (ões) do Projeto da USP neste município ( ) E quais foram os assuntos tratados nessa (s) reunião (reuniões)? .

6. Participou de alguma atividade de campo do Projeto da USP aqui no município?

R) Não conhece ou não ouviu falar de atividades de campo ( ) (Pule para pergunta 8) Não participou de atividades de campo ( ) (Pule para pergunta 8) 
Sim, participou de atividades de campo aqui no município ( ) E quais foram as atividades de campo de que o Sr. (a Sra ${ }^{\text {. }}$, você) participou aqui no município? . . . . . . . . . . .

(Explore a pergunta) Participou de alguma atividade do Projeto USP em alguma escola? Ou com alguma associação de agricultores, de artesãos, de mulheres? . . . . . . . .

7. O Sr. (a Srä., você) participou do mutirão de limpeza do Projeto da USP?

( ) Não participou. (Pule para pergunta 8)

( ) Sim, participou. (Continue a perguntar). O Sr. (a Srª., você) sabe se foi feito outro mutirão de limpeza no município, depois daquele mutirão do Projeto USP?

( ) Não sabe dizer/ desconhece se houve outro mutirão. (Pule para perg. 8)

( ) Não foi feito outro mutirão de limpeza. (Pule para pergunta 8)

( ) Sim, foi feito outro mutirão de limpeza no município(Continue a pergunta)

(Continuação da pergunta 7 Como foi feito esse outro mutirão? (Explorar a pergunta). Em que bairro ou em que ruas do município foi feito esse outro mutirão? Quem foram as pessoas que participaram desse outro mutirão? Que tipo de limpeza foi feita nesse outro mutirão: limpeza da rua, da praça, de terrenos vazios, da caixa d'água?

R).

8. Houve alguma mudança para o Sr. (a Srä., você) depois que o Projeto da USP começou aqui no município?

R) Não houve mudança ( )

Sim, houve mudança ( ) E que mudança foi essa? (Explorar a pergunta). Foi uma mudança que aconteceu mais para o Sr. (a Srª., você)? Ou foi uma mudança que aconteceu dentro da sua família? Foi uma mudança que aconteceu no interior da sua casa? . . . . . . .

9. Na opinião do Sr. (da Sr ${ }^{\mathrm{a}}$., na sua opinião), as pessoas estão cuidando mais do meio ambiente aqui no município ou esse cuidado ainda não acontece?

R) . 
10. O jardim das casas está sendo bem cuidado pelos moradores ou existe falta de conservação?

R)

11. A água usada pelas pessoas que pescam ou tomam banho, aqui no município, está em melhores condições ou não houve mudança?

R)

12. Depois que começou o Projeto da USP, a coleta de lixo melhorou aqui no município? (Explorar a pergunta).

R)

13. E a limpeza da cidade, melhorou depois que o Projeto da USP começou no município? (Explorar a pergunta).

R)

14. Na opinião do Sr. (da Srä., na sua opinião), o que faltou no Projeto da USP aqui no município?

R)

15) O Sr. (a Sra Projeto da USP?

R) .

OBSERVAÇÕES FINAIS DO ENTREVISTADOR:

Data de realização da entrevista:

Nome do Entrevistador: 